\title{
An Investigation into the Perceptions of Veterinarians towards Perioperative Pain Management in Calves
}

\author{
Ria van Dyke $\mathbb{D}$, Melanie Connor $\mathbb{D}^{\mathbb{D}}$ and Amy Miele * \\ Division of Animal Behaviour and Welfare, The Royal (Dick) School of Veterinary Studies, \\ University of Edinburgh, Roslin EH25 9RG, UK; ria.vandyke@gmail.com (R.v.D.); m.connor@irri.org (M.C.) \\ * Correspondence: amy.miele@ed.ac.uk
}

check for updates

Citation: van Dyke, R.; Connor, M.; Miele, A. An Investigation into the Perceptions of Veterinarians towards Perioperative Pain Management in Calves. Animals 2021, 11, 1882. https://doi.org/10.3390/ani11071882

Academic Editors: Brooklyn Wagner and Catie Cramer

Received: 26 April 2021

Accepted: 22 June 2021

Published: 24 June 2021

Publisher's Note: MDPI stays neutral with regard to jurisdictional claims in published maps and institutional affiliations.

Copyright: (c) 2021 by the authors. Licensee MDPI, Basel, Switzerland. This article is an open access article distributed under the terms and conditions of the Creative Commons Attribution (CC BY) license (https:// creativecommons.org/licenses/by/ $4.0 /)$.
Simple Summary: Despite developments in animal welfare science regarding perioperative pain management in calves (Bos taurus), there are concerns that current knowledge has not been adopted in practice. Given that the perceptions of veterinarians have implications for how the welfare needs of calves are assessed and managed in practice, this study sought to quantify veterinary perceptions towards perioperative pain management in calves, including barriers to its use and whether demographic differences may influence those perceptions. A nationwide survey was electronically distributed to veterinarians registered with the Veterinary Council of New Zealand. Veterinarians largely associated multimodal pain management with the greatest reduction in perioperative pain. Most veterinarians also perceived that postprocedural pain persists beyond $24 \mathrm{~h}$ for disbudding and castration and did not support the use of differential treatment based on developmental age. Despite this, certain barriers were identified for their potential to inhibit the use of pain management on-farm. While demographic differences were found to influence veterinary perceptions towards perioperative pain management, the findings revealed considerable support among veterinarians for improving pain mitigation in calves. Given the opportunity, veterinarians in New Zealand would likely support strengthening the minimum provisions afforded to calves in practice and policy.

Abstract: While veterinarians are instrumental to the welfare of calves (Bos taurus), limited knowledge exists concerning veterinary perceptions towards perioperative pain management in calves. As a part of a larger, nationwide study investigating the perceptions of veterinarians towards calf welfare, the current work sought to quantify veterinary perceptions towards perioperative pain management, including barriers to its use, and investigate demographic influences affecting those perceptions. An electronic mixed-methods survey was completed by 104 veterinarians registered with the Veterinary Council of New Zealand. The current work revealed that most veterinarians considered a multimodal approach as the most effective method for ameliorating perioperative pain in calves, rejected the practice of differential treatment based on developmental age, and perceived that postprocedural pain persists beyond $24 \mathrm{~h}$ for the majority of procedures included in the survey. Despite this, veterinarians identified certain barriers that may inhibit the provision of pain mitigation on-farm, including costs, inadequate recognition of pain, and ingrained farming practices. Certain demographic effects were found to influence perceptions towards perioperative pain management, including gender, the number of years since graduation, and species emphasis. Nevertheless, the current work demonstrated considerable support among veterinarians to improve pain management protocols during routine husbandry procedures. The asymmetries that exist between the current minimum provisions of perioperative pain management and veterinary perspectives suggest that substantive improvements are necessary in order to reconcile New Zealand's existing regulatory regime with developments in scientific knowledge.

Keywords: animal welfare; calves; veterinarians; pain; animal husbandry; pain management; perceptions 


\section{Introduction}

Unmitigated pain is associated with suffering and distress, and thus represents a critical welfare concern within farm animal practice [1-3]. While freedom from pain is considered a requisite for animal welfare [4-6], calves (Bos taurus) are often subjected to painful husbandry procedures without the provision of pain relief [7-10]. Young calves are particularly vulnerable to welfare compromise [11-13]. Given that routine husbandry procedures are often performed on calves at an early age without a developed adaptive immune system [14], painful stressors may suppress immune function and increase susceptibility to disease in immunologically naïve neonates [14-16]. Evidence suggests that pain mitigation may attenuate suppressed leukocyte function during such routine procedures in calves [16]. There is concern that unmitigated pain may lead to incapacitating pathophysiological effects that not only compromise welfare, but also increase the risk of morbidity and mortality $[13,17]$. Furthermore, there is evidence that noxious experiences during neonatal development may have systemic effects on nociceptive processing, resulting in hypersensitivity to pain later in life [18-20].

Invasive husbandry procedures are routinely performed on very young animals without pain relief on the basis of a misconception that younger animals experience less pain [21]. While developmental differences in the experience of pain have been studied explicitly with calves using behavioural and physiological indicators [18,22,23], such age-based comparisons are limited due to a fundamental problem with interpretation. Developmental changes in young animals may include changes in the sensitivity of certain indices used to assess pain, such as cortisol [4,24,25]. For this reason, different responses to the same pain index at different developmental ages does not definitively demonstrate changes in the severity of pain experienced [24]. While local anaesthesia has been found effective in managing the acute nociceptive pain during painful husbandry procedures [26-28], postprocedural pain arises due to the inflammatory processes initiated by tissue damage $[27,29]$. Given the complexity of the mechanisms involved in nociception, a multimodal approach that involves the administration of pharmaceutical agents before, during, and/or after a procedure has been described as best practice in mitigating perioperative pain $[21,27,29-34]$. Despite this, multimodal pain management is exceedingly rare in farm animal practice $[21,29,35,36]$.

Given that an association has been found between veterinary perceptions towards pain and the use of analgesic agents in practice $[37,38]$, the perceptions of veterinarians towards the welfare needs of calves have direct implications for how those needs are assessed and managed in practice [6,35]. Despite extensive research on the importance of multimodal protocols in the management of pain in companion animals [21,28,29,39-41], there are comparatively few studies on veterinary perspectives towards the management of perioperative pain in bovine species. Of the research available, most studies are focused on attitudes towards the acute pain phase associated with certain husbandry procedures $[42,43]$ and painful conditions $[38,43,44]$ in dairy cattle. In particular, very few studies have investigated veterinary perspectives towards a multimodal approach to pain management in calves $[35,36]$. Further, there are no published studies that have explored whether veterinarians support differential treatment based on developmental age, and this warrants further investigation.

The objective of this study was to investigate the perceptions of veterinarians towards perioperative pain management in calves. More specifically, this study sought: (i) to determine how different pain mitigation protocols are perceived across certain husbandry procedures; (ii) to examine the perceptions of veterinarians towards postprocedural pain in calves; (iii) to explore whether veterinarians support differential treatment based on the developmental age of a calf; (iv) to identify areas thought by veterinarians to serve as barriers to the provision of pain management on-farm; and (v) to determine whether certain demographic factors influence those perceptions. Meeting these research objectives will enable the findings to be used by researchers and educators to identify areas where veterinary estimation of pain in calves does not align with scientific knowledge, and by 
legislators as a measure of expert consensus on perioperative pain associated with routine husbandry procedures in calves.

\section{Materials and Methods}

Prior to commencement, ethical approval was obtained from the University of Edinburgh Human Ethical Review Committee (HERC_269-18).

\subsection{Survey Development}

Facilitated by the existing literature, a survey was developed through open dialogue with veterinarians, academics, and veterinary students. Initial pilot interviews were implemented with a small sample of veterinary students to test the survey for applicability and comprehensibility. The survey was then electronically distributed (Jisc Online Surveys) to a second sample of students for the purpose of pilot testing. In order to determine whether certain demographic effects influence perceptions towards perioperative pain management, the final version of the survey collected the following quantifiable characteristics: gender, birth year, graduation year, and species emphasis.

Respondents were asked to provide a pain score for different routine husbandry scenarios presented as single-item rating scales. While pain scales are a subjective measure, they offer an important contribution to pain evaluation because such measures enable the majority opinion of multiple informed assessors to be quantified [38] and provide valuable insights into where pain estimation may not align with current scientific knowledge [43]. The scenarios varied by husbandry procedure, the developmental age of the calf, and the type of pain relief administered. The husbandry procedures included: castration with rubber rings, castration with high tension bands, disbudding, and supernumerary teat removal. These procedures were selected due to their identification in the literature as painful [2,45-47]. The scenarios were based on regulatory proposals developed by the Ministry for Primary Industries (MPI) [48] or considered current practice at the time of survey development [49] (Table 1). To investigate perceptions towards multimodal pain management, respondents were asked to score pain depending on the presence or absence of local anaesthesia and/or postoperative analgesia. A 10-point rating scale was used to minimise the potential for central tendency bias [50]. Responses were assigned an incremental numerical value $(1=$ no pain at all, $10=$ most severe pain).

Table 1. Proposed welfare regulations or standards of practice in New Zealand regarding the provision of pain management for certain husbandry procedures at the time of survey development.

\begin{tabular}{|c|c|}
\hline Procedure & Regulation or Standard \\
\hline $\begin{array}{l}\text { Castration with rubber } \\
\text { rings }\end{array}$ & $\begin{array}{c}\text { Castration with a rubber ring can be used under } 6 \text { months of age } \\
\text { without pain relief. Over } 6 \text { months, local anaesthetic must be } \\
\text { provided }{ }^{\text {a }} \text { (effective } 1 \text { October 2018). }\end{array}$ \\
\hline $\begin{array}{l}\text { Castration with high } \\
\text { tension bands }\end{array}$ & $\begin{array}{l}\text { Castration with a high-tension band must be performed with the } \\
\text { provision of local anaesthetic at any age a (effective } 1 \text { October 2018). }\end{array}$ \\
\hline Disbudding & $\begin{array}{l}\text { Disbudding must be performed with the provision of local } \\
\text { anaesthetic at any age }{ }^{\text {a }} \text { (effective } 1 \text { October 2019). }\end{array}$ \\
\hline $\begin{array}{l}\text { Supernumerary teat } \\
\text { removal }\end{array}$ & $\begin{array}{l}\text { Supernumerary teat removal can be performed under } 6-10 \text { weeks } \\
\text { of age without pain relief. Over } 6-10 \text { weeks, pain relief is } \\
\text { recommended }{ }^{b} \text { (pain relief required over } 10 \text { weeks of age, effective } \\
27 \text { July 2020). }\end{array}$ \\
\hline
\end{tabular}

\footnotetext{
${ }^{a}$ Proposed calf welfare regulations [48] and ${ }^{b}$ standards of practice at the time of survey development in 2018 [49]. Current calf welfare regulations as of 2021 [51] are included in parenthesis.
}

Respondents were then asked to indicate the likely duration of postprocedural pain in calves across these husbandry procedures through the use of multiple-choice questions. This measure was adapted from Hambleton and Gibson's study [42], which investigated 
the opinions of veterinarians towards post-disbudding analgesia in calves, and modified to include the procedures in the scenario-based questions.

For the purpose of investigating whether veterinarians support differential treatment based on the developmental age of a calf, respondents were asked to provide the age beyond which it is necessary to provide pre-emptive local anaesthesia and/or postoperative analgesia for certain procedures through the use of multiple-choice questions.

In order to explore veterinary perceptions towards barriers to the provision of pain management on-farm, respondents were asked to identify which factors may serve as barriers to the use of pain relief among farmers. A 6-point Likert-type scale was developed to reduce the potential for neutral responding ( $1=$ strongly disagree, $6=$ strongly agree $)$. Potential barriers were selected based on their identification in the literature (Table 2). Respondents were given the opportunity to elaborate further if desired.

Table 2. Likert-type scale items adapted from the existing literature concerning potential barriers to the provision of pain management.

\begin{tabular}{cc}
\hline Scale Item & Adapted from \\
\hline Costs of pain management & {$[42,44,52-54]$} \\
\hline Costs of veterinary treatment & {$[52,55,56]$} \\
\hline Labour demand associated with administration & {$[42,52,57]$} \\
\hline Concern that drugs may affect production quality & {$[35,58-60]$} \\
\hline Concern that drugs may have side effects & {$[42,44,54,60-62]$} \\
\hline Drug licensing restrictions & {$[42,52,63]$} \\
\hline Limited knowledge on the available options & {$[46,52,64-66]$} \\
\hline Inadequate recognition of pain & {$[35,38,52,56]$} \\
\hline Ingrained farming practices & {$[42,52,65]$} \\
\hline
\end{tabular}

\subsection{Sampling}

The Veterinary Council of New Zealand (VCNZ) granted permission to recruit practising veterinarians. A list of 604 veterinarians was retrieved and compiled into a database (Microsoft Excel 2016). Inclusion in the database was based on veterinarians who displayed a direct e-mail address and were listed as currently operating in clinical practice in New Zealand. Given that the present study was developed in the wake of intense scrutiny towards calf welfare in New Zealand [11,67], along with subsequent legislative transformation, anonymous self-administration was enabled to reduce the perception of personal risk and enhance self-disclosure $[68,69]$. A cover letter introducing the nature of the research, along with a link to the survey (Jisc Online Surveys), was administered to all veterinarians included in the final database. This was followed two weeks later with a courtesy message thanking those who had responded and appealing to others to respond. This approach follows the general recommendations for survey protocol advocated by Dillman [70].

\subsection{Data Analysis}

Data was exported into the Statistical Package for the Social Sciences (SPSS Version 24). Main effects and interaction effects were considered significant at $p<0.05$. Sample demographics were reported as descriptive statistics. To explore gender differences for continuous variables, an independent samples t-test was utilised, with effect size reported as Cohen's $d$. For analysis of perceptions towards different pain management strategies, a general linear mixed model (GLMM) was fitted with the restricted maximum likelihood (REML) method to explore the factors affecting perceived pain ratings. The model was fitted with demographic factors, along with pain management strategy, as fixed effects and participant unique identifiers as a random effect. Pairwise interaction effects were investigated between all factors when preparing the model. Through multiple iterations, 
the model was simplified until only main effects and significant interactions remained. The significance of fixed effects was determined by type III Wald tests for main effects and type I for interaction effects. In order to explore the influence of demographic effects on perceptions towards postprocedural pain durations, ordinal logistic regression (OLR) was utilised. Odds ratios (ORs) were calculated as a measure of estimated effect size. The assumption of proportional odds was evaluated through the test of parallel lines, and multicollinearity was assessed using variance inflation factor (VIF). Perceptions regarding differential treatment were reported as descriptive statistics. Binary logistic regression (BLR) was then used to explore the influence of demographic effects on those responses. Response categories were consolidated to ensure the assumption of independence of irrelevant alternatives was met. A Spearman's rank order correlation was used to explore whether there was an association between perceptions towards postprocedural pain durations and differential treatment. Likert-type responses regarding barriers to the provision of pain management on-farm were reported as descriptive statistics. Mann-Whitney U tests were used for two sample comparisons (e.g., gender) and Kruskal-Wallis $\mathrm{H}$ tests for multilevel samples (e.g., years since graduation, species emphasis). Significance levels were subject to Bonferroni correction to reduce the impact of Type I errors. Homogeneity of variance was analysed using Levene's test. Multicollinearity was assessed through VIF. Respondents were also given the opportunity to elaborate further and responses which were most widely shared among veterinarians were reported.

\section{Results}

Of the 106 surveys returned, one submission with all missing entries, along with another submission with only demographic data provided, were excluded from the study. In total, 104 veterinarians were included in the final dataset.

\subsection{Demographic Data}

A breakdown of the sample demographics is included in Table 3. As might be expected there was a strong correlation between respondent age and years since graduation $(\mathrm{r}=0.96$; $p<0.001)$. Independent samples t-tests demonstrated that female veterinarians graduated more recently than male veterinarians $(p<0.001)$ and were also significantly younger $(p<0.001$; Figure 1). Chi-squared tests indicated that there were no significant differences between the number of male and female respondents specialised in a certain species $\left(\chi^{2}(2)=4.53, p=0.104\right)$.

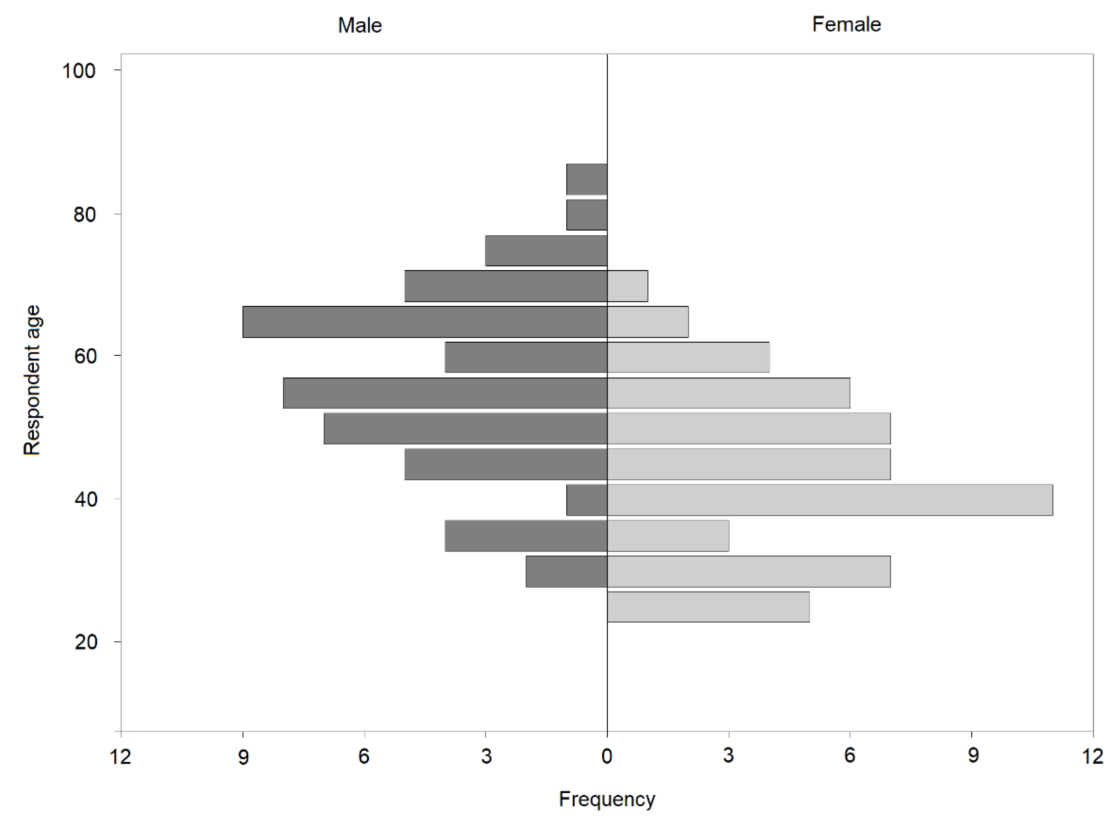

Figure 1. Gender and age distribution of veterinary respondents. 
Table 3. An overview of the sample demographics.

\begin{tabular}{ccc}
\hline Demographic Variable & $\boldsymbol{n}$ & \% \\
\hline Years since graduation $(N=103 ; \overline{\mathrm{X}}=23.75 ; \sigma=14.23)$ & 23 & 22.2 \\
$0-10$ & 21 & 20.5 \\
$11-20$ & 29 & 28.0 \\
$21-30$ & 15 & 14.7 \\
$31-40$ & 15 & 14.7 \\
41 and over & & \\
Gender $(N=102)$ & 49 & 52.0 \\
Male & 53 & \\
Female & & 11.6 \\
$24-30$ & 12 & 20.2 \\
$31-40$ & 21 & 22.2 \\
$41-50$ & 23 & 24.1 \\
$51-60$ & 25 & 21.4 \\
\hline Age $(N=103$ and over & 25 & \\
\hline a $=13.75)$ & & 41.0 \\
Large animal practice & 41 & 37.0 \\
Mixed animal practice & 37 & 22.0 \\
\hline
\end{tabular}

\subsection{Perceptions towards Perioperative Pain Management}

The GLMM model was fitted with demographic factors, pain management strategies, and pairwise interactions as fixed effects. The model determined that the effect of pain management was highly significant across all procedures (all $p<0.001$ ), with multimodal pain mitigation associated with the greatest reduction of perceived pain (Table 4).

Table 4. Estimated marginal means (EMM) and standard error of the means (SEM) for the perceived pain scores ${ }^{a}$ of veterinarians across certain husbandry procedures by pain management protocol: none, local anaesthetic only (LA), or multimodal (MM) ${ }^{b}$, with demographic variables modelled as fixed effects ${ }^{c}$.

\begin{tabular}{|c|c|c|c|c|c|}
\hline \multicolumn{6}{|c|}{$\begin{array}{c}\text { Pain Management Protocol } \\
\text { EMM (SEM) }\end{array}$} \\
\hline Procedure & None & LA & $\mathbf{M M}$ & $F$ & $p$ \\
\hline $\begin{array}{c}\text { Castration-rubber } \\
\text { rings } \\
(N=103)\end{array}$ & $7.86(0.11)$ & $5.12(0.11)$ & $3.25(0.11)$ & $F_{2,861}=466.96$ & $<0.001$ \\
\hline $\begin{array}{l}\text { Castration-high } \\
\text { tension bands } \\
(N=90)\end{array}$ & - & $5.75(0.18)$ & $3.88(0.18)$ & $F_{1,331}=57.70$ & $<0.001$ \\
\hline $\begin{array}{l}\text { Supernumerary } \\
\text { teat removal } \\
\quad(N=97)\end{array}$ & $6.27(0.20)$ & $4.00(0.13)$ & $2.42(0.13)$ & $F_{2,452}=119.87$ & $<0.001$ \\
\hline $\begin{array}{l}\text { Disbudding }(N= \\
102)\end{array}$ & - & $5.61(0.14)$ & $3.30(0.14)$ & $F_{1,377}=136.08$ & $<0.001$ \\
\hline $\begin{array}{l}\text { ignificance: } p<0.05 \text {. } \\
\text { Perceived pain scores } \\
\text { rocedure, the estimate } \\
\text { equirement (none or L } \\
\text { ender, the number of } \\
\text { ontravene the minimu } \\
\text { rovided, and these are }\end{array}$ & $\begin{array}{l}\text { 1: standard } \\
\text { measured o } \\
\text { ect of pain } \mathrm{m} \\
\text { d MM (local } \\
\text { s since grad } \\
\text { quirements } \\
\text { cated by a da }\end{array}$ & $\begin{array}{l}\text { of the mea } \\
0 \text {-point scal } \\
\text { gement prot } \\
\text { esthesia and } \\
\text { on, and spec } \\
\text { the Anima } \\
\text { line. }\end{array}$ & $\begin{array}{l}F\left(\mathrm{df}_{1}, \mathrm{df}_{2}\right)= \\
\text { no pain at all } \\
\text { vas comparec } \\
\text { perative anal } \\
\text { nphasis. In c } \\
\text { are Act } 1999\end{array}$ & $\begin{array}{l}\text { alue); df: degre } \\
=\text { most severe pa } \\
\text { ween the minim } \\
\text { a). }{ }^{c} \text { Demograph } \\
\text { r to ensure the } \\
\text { tain response op }\end{array}$ & $\begin{array}{l}\text { of freedon } \\
\text { b For eac } \\
\text { legislativ } \\
\text { ixed effect } \\
\text { ey did no }\end{array}$ \\
\hline
\end{tabular}


Across all pain management strategies, female veterinarians had significantly higher perceived pain scores than male veterinarians for supernumerary teat removal $\left(F_{1,452}=6.92\right.$; $p=0.009)$ and disbudding $\left(F_{1,377}=8.80 ; p=0.003\right)$. There was also a significant effect of the number of years since graduation on perceived pain scores for disbudding $\left(F_{1,388}=17.07\right.$; $p<0.001$ ), which indicates that more recently graduated respondents perceived more pain. Across all procedures, an interaction effect was found between gender and years since graduation (Table 5). Male veterinarians had lower pain scores as the number of years since graduation increased (all $p<0.05$; Table 5 ). No significant effect was found between years since graduation and females across all procedures $(p>0.05)$, which suggests that pain ratings were consistent among females, irrespective of the number of years since graduation. Significant differences in perceived pain scores for castration with rubber rings $\left(F_{2,860}=5.36 ; p=0.005\right)$ and supernumerary teat removal $\left(F_{2,452}=23.62 ; p<0.001\right)$ were found between veterinarians working in the three types of veterinary practice, with the largest differences found between veterinarians working in companion animal practice and veterinarians working in large animal practice (Table 6).

Table 5. The interaction effect between gender and years since graduation on the perceived pain scores ${ }^{\text {a }}$ of veterinarians across certain husbandry procedures.

\begin{tabular}{cccc}
\hline & & \multicolumn{2}{c}{ Gender $\times$ Years Since Graduation } \\
\hline Procedure & Gender & $\boldsymbol{T}$ & $\boldsymbol{p}$ \\
\hline Castration-rubber rings & Male & $t(860)=-3.45$ & 0.001 \\
$(N=103)$ & Female & $t(860)=0.84$ & 0.404 \\
\hline Castration-high tension bands & Male & $t(330)=-4.45$ & $<0.001$ \\
$(N=90)$ & Female & $t(330)=0.51$ & 0.614 \\
\hline Supernumerary teat removal & Male & $t(451)=-1.42$ & 0.157 \\
$(N=97)$ & Female & $t(451)=1.152$ & 0.131 \\
\hline Disbudding & Male & $t(376)=-4.02$ & $<0.001$ \\
$(N=102)$ & Female & $t(376)=-0.55$ & 0.581 \\
\hline
\end{tabular}

Significance: $p<0.05$; Direction of effect: negative $t$ values indicate that senior veterinarians perceived lower pain scores than their more recently graduated peers. ${ }^{\text {a }}$ Perceived pain scores were measured on a 10-point scale $(1=$ no pain at all; $10=$ most severe pain).

Table 6. Estimated marginal means (EMM) and standard errors of the mean (SEM) for the perceived pain scores ${ }^{a}$ of veterinarians across certain husbandry procedures by species emphasis.

\begin{tabular}{|c|c|c|c|c|c|c|}
\hline \multicolumn{7}{|c|}{ Species Emphasis EMM (SEM) } \\
\hline Procedure & COM & MIX & LGE & Predictor & $t$ & $p$ \\
\hline $\begin{array}{l}\text { Castration-rubber rings } \\
\qquad(N=103)\end{array}$ & $5.69(0.13)$ & $5.48(0.10)$ & $5.06(0.10)$ & $\begin{array}{l}\text { COM-LGE } \\
\text { MIX-LGE }\end{array}$ & $\begin{array}{l}t(860)=-2.75 \\
t(860)=-2.79\end{array}$ & $\begin{array}{l}0.006 \\
0.005\end{array}$ \\
\hline $\begin{array}{c}\text { Castration-high tension bands } \\
\qquad(N=90)\end{array}$ & $4.88(0.27)$ & $5.09(0.20)$ & $4.48(0.20)$ & $\begin{array}{l}\text { COM-LGE } \\
\text { MIX-LGE }\end{array}$ & $\begin{array}{l}t(330)=-0.35 \\
t(330)=-2.17\end{array}$ & $\begin{array}{l}0.729 \\
0.031\end{array}$ \\
\hline $\begin{array}{l}\text { Supernumerary teat removal } \\
\qquad(N=97)\end{array}$ & $4.90(0.18)$ & $4.02(0.13)$ & $3.35(0.14)$ & $\begin{array}{l}\text { COM-LGE } \\
\text { MIX-LGE }\end{array}$ & $\begin{array}{l}t(451)=-6.04 \\
t(451)=-3.52\end{array}$ & $\begin{array}{l}<0.001 \\
<0.001\end{array}$ \\
\hline $\begin{array}{l}\text { Disbudding } \\
(N=102)\end{array}$ & $4.83(0.22)$ & $4.32(0.16)$ & $4.22(0.16)$ & $\begin{array}{l}\text { COM-LGE } \\
\text { MIX-LGE }\end{array}$ & $\begin{array}{l}t(377)=-2.23 \\
t(377)=-0.44\end{array}$ & $\begin{array}{l}0.026 \\
0.659\end{array}$ \\
\hline
\end{tabular}

Significance: $p<0.05$; COM: companion animal practice, MIX: mixed animal practice, LGE: large animal practice; Direction of effect: negative $t$ values indicate a reduction in perceived pain scores between the tested predictor (either COM or MIX) and LGE. ${ }^{\text {a }}$ Perceived pain scores were measured on a 10 -point scale $(1=$ no pain at all; $10=$ most severe pain $)$.

\subsection{Perceptions towards Postprocedural Pain}

Veterinarians were asked for their opinion on the likely duration of postprocedural pain following four painful husbandry procedures (Table 7). Most veterinarians perceived that postprocedural pain persists beyond $24 \mathrm{~h}$ for disbudding $(74.5 \% ; n=76 ; \bar{X}=5.01$; 
$\left.\sigma_{\overline{\mathrm{X}}}=0.12\right)$, castration with rubber rings $\left(65.5 \% ; n=66 ; \bar{X}=4.51 ; \sigma_{\overline{\mathrm{X}}}=0.15\right)$, and castration with high tension bands $\left(63.3 \% ; n=57 ; \bar{X}=4.56 ; \sigma_{\overline{\mathrm{x}}}=0.15\right)$. There was less agreement between responses for supernumerary teat removal, with most veterinarians perceiving pain durations of less than $24 \mathrm{~h}\left(65.6 \% ; n=63 ; \bar{X}=3.72 ; \sigma_{\overline{\mathrm{x}}}=0.15\right)$.

Table 7. The percentage and number of veterinarians that specified postprocedural pain durations across certain husbandry procedures.

\begin{tabular}{|c|c|c|c|c|c|c|}
\hline \multirow{2}{*}{ Procedure } & \multicolumn{6}{|c|}{ Postprocedural Pain Duration } \\
\hline & None & $<6 \mathrm{~h}$ & $<12 \mathrm{~h}$ & $<24 \mathrm{~h}$ & $>24 \mathrm{~h}$ & $>48 \mathrm{~h}$ \\
\hline $\begin{array}{l}\text { Castration- } \\
\text { rubber rings } \\
\quad(N=104)\end{array}$ & - & $\begin{array}{c}20.2 \% \\
(n=21)\end{array}$ & $\begin{array}{c}7.7 \% \\
(n=8)\end{array}$ & $\begin{array}{c}8.7 \% \\
(n=9)\end{array}$ & $\begin{array}{c}27.9 \% \\
(n=29)\end{array}$ & $\begin{array}{c}35.6 \% \\
(n=37)\end{array}$ \\
\hline $\begin{array}{l}\text { Castration- } \\
\text { high tension bands }(N=90)\end{array}$ & - & $\begin{array}{c}17.8 \% \\
(n=16)\end{array}$ & $\begin{array}{l}12.2 \% \\
(n=11)\end{array}$ & $\begin{array}{c}6.7 \% \\
(n=6)\end{array}$ & $\begin{array}{l}23.3 \% \\
(n=21)\end{array}$ & $\begin{array}{c}40.0 \% \\
(n=36)\end{array}$ \\
\hline $\begin{array}{l}\text { Supernumerary teat } \\
\text { removal } \\
(N=96)\end{array}$ & $\begin{array}{c}2.1 \% \\
(n=2)\end{array}$ & $\begin{array}{c}25.0 \% \\
(n=24)\end{array}$ & $\begin{array}{c}20.8 \% \\
(n=20)\end{array}$ & $\begin{array}{c}19.8 \% \\
(n=19)\end{array}$ & $\begin{array}{c}15.6 \% \\
(n=15)\end{array}$ & $\begin{array}{c}16.7 \% \\
(n=16)\end{array}$ \\
\hline $\begin{array}{l}\text { Disbudding } \\
(N=102)\end{array}$ & - & $\begin{array}{l}5.9 \% \\
(n=6)\end{array}$ & $\begin{array}{c}9.8 \% \\
(n=10)\end{array}$ & $\begin{array}{c}9.8 \% \\
(n=10)\end{array}$ & $\begin{array}{l}26.5 \% \\
(n=27)\end{array}$ & $\begin{array}{c}48.0 \% \\
(n=49)\end{array}$ \\
\hline
\end{tabular}

A dashed line represents a response option that was not selected by any of the respondents.

An OLR model, fitted with demographic factors, demonstrated that across all procedures, an increase in years since graduation was associated with lower perceived postprocedural pain durations (all $p<0.05$; Table 8 ). Species emphasis also had a significant effect on veterinary perceptions towards postprocedural pain. With the exception of disbudding, veterinarians working in large animal practice were less likely to perceive greater postprocedural pain durations than veterinarians working in companion animal practice (all $p<0.05$; Table 9). Veterinarians working in large animal practice were also less likely to perceive greater postprocedural pain durations for supernumerary teat removal than veterinarians working in mixed animal practice $(p=0.008$; Table 9$)$. The effect of gender on perceptions of postprocedural pain was not found to be significant $(p>0.05)$.

Table 8. A comparison of the impact of number of years since graduation ${ }^{\text {a }}$ on the perceived postprocedural pain durations of veterinarians across certain husbandry procedures.

\begin{tabular}{ccc}
\hline Procedure & $p$ & OR (95\% CI) \\
\hline Castration-rubber rings $(N=98)$ & 0.012 & $0.96(0.93,0.99)$ \\
Castration-high tension bands $(N=85)$ & 0.045 & $0.96(0.93,1.00)$ \\
Supernumerary teat removal $(N=91)$ & 0.036 & $0.96(0.93,1.00)$ \\
Disbudding $(N=96)$ & $<0.001$ & $0.94(0.90,0.97)$
\end{tabular}

Significance: $p<0.05$; OR: odds ratio (per year since graduation); CI: confidence interval. ${ }^{a}$ Number of years since graduation ranging between 0 and $58(\mu=23.75, \sigma=14.23)$.

\subsection{Perceptions towards Differential Treatment}

Veterinarians were asked for their opinion on the age beyond which it is necessary to provide pre-emptive local anaesthesia and/or postoperative analgesia in calves across certain painful procedures. With regard to the procedures that do not legally require local anaesthesia, the majority of veterinarians perceived that local anaesthesia should be provided for both castration with rubber rings $(59.2 \% ; n=61)$ and supernumerary teat removal $(57.1 \% ; n=56)$, irrespective of developmental age. Further, the greatest proportion of veterinarians supported the use of postoperative analgesia at any age for disbudding $(68.3 \% ; n=69)$, castration with high-tension bands $(64.4 \% ; n=57)$, castration with rubber-rings $(55.3 \% ; n=57)$, and supernumerary teat removal $(44.3 \% ; n=43)$ (Table 10$)$. Spearman's rank order correlation demonstrated that across all procedures, a strong correlation was found between veterinary perceptions towards postprocedural pain and the 
age beyond which calves should be provided with postoperative analgesia (all $p<0.001)$. This finding demonstrates that veterinarians that perceived greater postprocedural pain durations were likely to indicate stronger support for the use of postoperative analgesia at any developmental age.

Table 9. Mean (SD) perceived postprocedural pain durations of veterinarians across certain husbandry procedures by species emphasis.

\begin{tabular}{|c|c|c|c|c|c|c|}
\hline \multicolumn{7}{|c|}{ Species Emphasis } \\
\hline Procedure & COM & MIX & LGE & Predictor & $p$ & OR $(95 \% \mathrm{CI})$ \\
\hline \multirow{2}{*}{$\begin{array}{l}\text { Castration-rubber rings } \\
\qquad(N=98)\end{array}$} & \multirow{2}{*}{$5.18(1.30)$} & \multirow{2}{*}{$4.46(1.56)$} & \multirow{2}{*}{$4.20(1.54)$} & COM-LGE & 0.026 & $3.26(1.15,9.23)$ \\
\hline & & & & MIX-LGE & 0.874 & $1.07(0.47,2.45)$ \\
\hline \multirow{2}{*}{$\begin{array}{c}\text { Castration-high tension bands } \\
\qquad(N=85)\end{array}$} & \multirow[b]{2}{*}{$5.16(1.39)$} & \multirow[b]{2}{*}{4.64 (1.56) } & \multirow[b]{2}{*}{4.09 (1.54) } & COM-LGE & 0.046 & $3.15(1.02,9.68)$ \\
\hline & & & & MIX-LGE & 0.161 & $1.90(0.77,4.66)$ \\
\hline \multirow{2}{*}{$\begin{array}{l}\text { Supernumerary teat removal } \\
\qquad(N=91)\end{array}$} & \multirow[b]{2}{*}{$4.45(1.32)$} & \multirow[b]{2}{*}{$3.91(1.38)$} & \multirow[b]{2}{*}{$3.08(1.40)$} & COM-LGE & 0.002 & $5.23(1.81,15.07)$ \\
\hline & & & & MIX-LGE & 0.008 & $3.29(1.37,7.89)$ \\
\hline \multirow{2}{*}{$\begin{array}{l}\text { Disbudding } \\
(N=96)\end{array}$} & \multirow{2}{*}{$5.24(0.94)$} & \multirow{2}{*}{$5.11(1.24)$} & \multirow{2}{*}{$4.80(1.29)$} & COM-LGE & 0.843 & $1.11(0.38,3.25)$ \\
\hline & & & & MIX-LGE & 0.629 & $1.24(0.51,3.00)$ \\
\hline
\end{tabular}

Significance: $p<0.05$; SD: standard deviation; COM: companion animal practice, MIX: mixed animal practice, LGE: large animal practice; OR: odds ratio; $\mathrm{CI}$ : confidence interval.

Table 10. The percentage (number) of veterinarians that identified an age beyond which it is necessary to provide postoperative analgesic for calves across certain husbandry procedures.

\begin{tabular}{|c|c|c|c|c|c|c|}
\hline Procedure & Any Age & $>2 w$ & $>8 w$ & $>4 \mathrm{~m}$ & $>6 \mathrm{~m}$ & None \\
\hline $\begin{array}{c}\text { Castration-rubber } \\
\text { rings }(N=103)\end{array}$ & $\begin{array}{c}55.3 \% \\
(n=57)\end{array}$ & $\begin{array}{c}17.5 \% \\
(n=18)\end{array}$ & $\begin{array}{c}12.6 \% \\
(n=13)\end{array}$ & $\begin{array}{c}2.9 \% \\
(n=3)\end{array}$ & $\begin{array}{c}1.0 \% \\
(n=1)\end{array}$ & $\begin{array}{c}10.7 \% \\
(n=11)\end{array}$ \\
\hline $\begin{array}{c}\text { Castration-high } \\
\text { tension bands }(N=89)\end{array}$ & $\begin{array}{c}64.0 \% \\
(n=57)\end{array}$ & $\begin{array}{c}11.2 \% \\
(n=10)\end{array}$ & $\begin{array}{c}16.9 \% \\
(n=15)\end{array}$ & $\begin{array}{c}3.4 \% \\
(n=3)\end{array}$ & $\begin{array}{c}0 \% \\
(n=0)\end{array}$ & $\begin{array}{c}4.5 \% \\
(n=4)\end{array}$ \\
\hline $\begin{array}{l}\text { Supernumerary teat } \\
\text { removal }(N=97)\end{array}$ & $\begin{array}{c}44.3 \% \\
(n=43)\end{array}$ & $\begin{array}{l}17.5 \% \\
(n=17)\end{array}$ & $\begin{array}{c}13.4 \% \\
(n=13)\end{array}$ & $\begin{array}{c}10.3 \% \\
(n=10)\end{array}$ & $\begin{array}{l}2.1 \% \\
(n=2)\end{array}$ & $\begin{array}{c}12.4 \% \\
(n=12)\end{array}$ \\
\hline $\begin{array}{l}\text { Disbudding } \\
(N=101)\end{array}$ & $\begin{array}{c}68.3 \% \\
(n=69)\end{array}$ & $\begin{array}{c}6.9 \% \\
(n=7)\end{array}$ & $\begin{array}{c}11.9 \% \\
(n=12)\end{array}$ & $\begin{array}{l}5.0 \% \\
(n=5)\end{array}$ & $\begin{array}{l}2.0 \% \\
(n=2)\end{array}$ & $\begin{array}{l}5.9 \% \\
(n=6)\end{array}$ \\
\hline
\end{tabular}

A BLR model, fitted with demographic factors, determined that veterinarians working in companion animal practice were 3.64 times more likely to perceive the provision of local anaesthesia as necessary for castration with rubber rings and 7.35 times more likely for supernumerary teat removal than veterinarians working in large animal practice $(95 \%$ CI $(1.08,12.20) ; p=0.037$ and $95 \%$ CI $(2.02,26.03) ; p=0.002$, respectively). Further, veterinarians working in companion animal practice were 7.19 times more likely to perceive the provision of postoperative analgesia necessary for supernumerary teat removal at any developmental age than veterinarians working in large animal practice $(95 \%$ CI $(2.14,23.81)$; $p=0.001$ ). A per year increase in years since graduation was associated with a 0.93 times reduction in odds that veterinarians would perceive postoperative analgesic as necessary at any age following disbudding $(95 \%$ CI $(0.89,0.97) ; p<0.001)$. The effect of gender on perceptions towards differential treatment was not found to be significant (all $p>0.05$ ).

\subsection{Perceived Barriers to the Provision of Pain Management}

Perceived barriers to the provision of pain management on-farm with the greatest level of agreement among veterinarians included the costs associated with pain management, the costs associated with veterinary administration, inadequate recognition of pain, and ingrained practices (Figure 2). The barriers perceived as least likely to influence the provision of pain relief on-farm included concerns for the impact of drug residues on production quality and concerns that drugs may have side effects (Figure 2). MannWhitney $U$ tests indicated that female veterinarians were significantly more likely than male veterinarians to perceive ingrained farm practices as a barrier to the provision of pain 
management $(p=0.033)$. Kruskal-Wallis H tests, followed by Mann-Whitney U tests for post hoc pairwise comparisons with Bonferroni correction $(0.05 / 10=0.005)$, showed that inadequate recognition of pain was perceived to be a greater barrier to the provision of pain relief on-farm by veterinarians who had graduated within the past 20 years compared to more senior veterinarians (0-10 years: $p=0.002$; $11-20$ years: $p<0.001)$. Further, veterinarians that had graduated within the past 10 years perceived ingrained farming practices as a greater barrier to the provision of pain relief on-farm than their more senior peers $(p=0.003$ Post hoc pairwise comparisons with Bonferroni correction $(0.05 / 3=0.017)$ undertaken with the three practice types demonstrated that veterinarians working in small animal practice were significantly more likely to perceive that concerns regarding drug residues on production quality may present a barrier to the provision of pain relief on-farm than veterinarians working in large animal practice $(p=0.003)$.

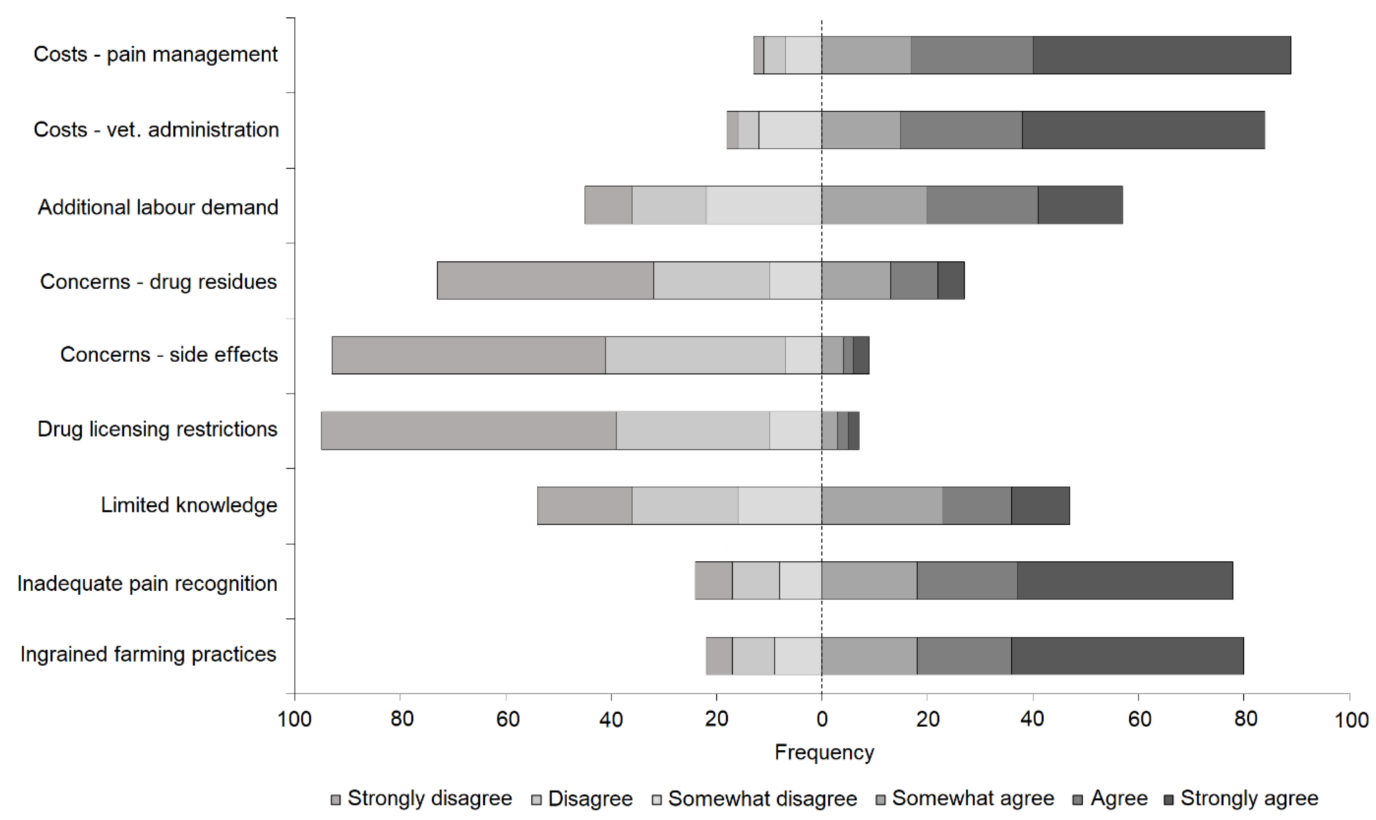

Figure 2. The number of veterinarians that perceived certain factors as barriers to the provision of pain management on-farm, where the dashed line represents the point between disagreement and agreement based on responses to a 6-point Likert-type scale.

Respondents were given the opportunity to elaborate on additional barriers to the provision of pain management that were not included in the scale. Of the 16 qualitative responses, the most representative considerations included concerns for how restricted veterinary medicine (RVM) may limit the use of pain management on-farm, with lay contractors requiring "a system/authorisation to access and use RVM". Further concerns included a "lack of understanding of the benefits of pain relief beyond just welfare", a "lack of empathy", and "disorganisation" on-farm. Respondents were also concerned with the normalisation of procedures without pain mitigation due to the accessibility of lay contractors "with apparent expertise advertising services without pain relief, which legitimises the practice".

\section{Discussion}

This paper is part of a larger, nationwide study exploring veterinary perceptions towards calf welfare in New Zealand [67]. The aim of this study was to investigate current thinking among veterinarians towards perioperative pain in calves.

\subsection{Perceptions towards Perioperative Pain Management}

Veterinarians in the current study associated multimodal pain management with a significant reduction of pain in calves when compared with no pain relief or local anaesthesia 
alone, which is consistent with the literature [27,33,71,72]. In line with scientific knowledge, the New Zealand Veterinary Association has identified that husbandry procedures that involve tissue damage are painful, affirming that analgesia must be included in the planning for all surgical procedures and continued for an appropriate duration following the procedure [73]. Although the benefits of multimodal protocols are well-established [21,27,29-32], multimodal pain management in calves is seldom used in practice $[21,29,35,36]$, which raises concerns regarding barriers to its' use.

In the current work, female veterinarians scored pain significantly higher than male veterinarians for supernumerary teat removal and disbudding, a finding that has been frequently reported $[36,38,42,43,62,74,75]$. While the role of empathy is outside the scope of the current work, previous studies have found that empathy may underpin perceptions of animal pain $[63,76]$, with a greater capacity among females to engage in affective resonance with animals $[77,78]$. In line with previous studies $[38,42,43,65,74,75,79]$, more recent veterinary graduates scored pain higher than their more senior colleagues for disbudding. Moreover, more recently graduated males perceived greater pain than their male colleagues. These findings may indicate that more recent veterinary graduates have greater access to developments in the scientific literature or that a greater emphasis has been placed on perioperative pain in the veterinary curricula in recent years. Veterinarians working in companion and mixed animal practice scored pain higher than veterinarians working in large animal practice across half of the procedures in question. While veterinarians are trained to consider animal health at the individual level, veterinarians in large animal practice are often tasked with managing animal health on a collective level [80]. This shift towards collective care places a greater emphasis on the utility or instrumental value of animals rather than the affective state of individual animals [81,82], which has important implications for the level of pain management afforded to calves in practice $[35,37,38]$.

\subsection{Perceptions towards Postprocedural Pain}

The majority of veterinarians in the current work perceived that postprocedural pain persists beyond $24 \mathrm{~h}$ for most painful husbandry procedures in question, which is supported by the scientific literature $[2,22,39,40,83-85]$. However, where pain management is required for painful husbandry procedures, regulations often focus on the experience of acute pain, with little consideration for pain that may persist beyond the perioperative period. Very few studies have focused on veterinary perceptions towards postoperative analgesic use and the extent to which it is adopted in practice. Although earlier research has indicated that postoperative analgesic use is limited $[10,38,64]$, there is scope for researchers to investigate how these perspectives and practices may have shifted over time. The present study explored potential barriers to the management of pain on-farm more generally, and this is discussed later (see Section 4.4).

Consistent with previous studies $[38,42,43,54]$, more recent veterinary graduates perceived longer postprocedural pain durations than their more senior colleagues. As previously mentioned, it is important to recognise the influence of animal welfare science on the veterinary curricula over time [86,87], which reinforces the need for continuing professional development to capture emerging scientific knowledge. Moreover, veterinarians working in large animal practice perceived significantly lower postprocedural pain durations than veterinarians working in companion animal practice, with the exception of disbudding. This finding indicates that the perceptions of veterinarians towards postoperative pain may be influenced by their work type. In line with these findings, previous studies have reported that students aspiring to work in specialisations outside of large animal practice rated higher pain in cattle [75] and shared greater concern towards farm animal welfare [81] than those that elected to work in large animal practice. Given that perceptions towards postprocedural pain will have implications for the use of postoperative pain relief in practice $[37,38]$, there is scope for further investigation into these trends within the profession. 


\subsection{Perceptions towards Differential Treatment}

Veterinarians in the present study largely perceived that all calves have the capacity to suffer from unmitigated pain and supported a multimodal approach to ameliorating perioperative pain in calves, irrespective of developmental age. This finding reveals that most veterinarians rejected the ontogeny of sentience as a basis for differential treatment in calves and highlights the discord between current regulatory standards and veterinary perspectives. However, differential treatment based on developmental age is common practice. For instance, supernumerary teat removal can be performed on young calves under 10 weeks of age without any pain relief, despite teat removal being considered a significant surgical procedure [51]. While scientific understanding of pain in cattle has developed in recent years to recognise pain and distress in young calves following painful husbandry procedures $[34,71,88,89]$, the use of pain relief has been reported as less frequent in younger calves $[90,91]$. This may be due to the misconceptions that exist in the use of pain management in young farm animals, including the belief that younger animals experience less pain [60]. It is also possible that pain relief may be used less frequently in younger calves due to the ease of handling younger animals $[64,66]$ and the fewer regulatory welfare provisions afforded to younger calves. Despite this, across all procedures, greater perceived pain durations were strongly correlated with increased support for the use of postoperative analgesia at any developmental age. As with previous studies [38,54], this indicates that an increased ability to recognise a procedure as having the potential to cause prolonged pain is likely to result in increased administration of analgesic agents to mitigate postoperative pain. Indeed, respondents who did not support the use of postoperative analgesia assigned significantly lower scores for postprocedural pain for all procedures in question, suggesting that a key motivator for the use of analgesic agents is the veterinarian's own perception of the pain that the animal is suffering [38].

While most veterinarians did not support differential treatment based on developmental age, certain demographic effects were found to influence those perceptions. Senior veterinarians were less likely to perceive the use of postoperative analgesia as necessary at any age following disbudding. This finding echoes Hambleton and Gibson's [42] report that stronger support was found among more recent veterinary graduates for the compulsory use of analgesic agents to reduce post-disbudding pain in calves. Further, veterinarians working in large animal practice were less likely to perceive local anaesthesia as necessary at any developmental age for castration with rubber rings and supernumerary teat removal, and less likely to perceive postoperative analgesia to be necessary following supernumerary teat removal than veterinarians working in companion animal practice.

\subsection{Perceived Barriers to the Provision of Pain Management}

To facilitate the development of strategies targeted at improving the uptake of practices that alleviate perioperative pain, it is important to consider the barriers that may impact upon such efforts [6]. A range of barriers to the provision of pain relief on-farm were identified, including the additional costs associated with pain mitigation, which is reinforced in the literature [60,64,90-94]. This highlights the complex, often competing, interests that veterinarians must navigate as they balance their professional obligations to safeguard the economic interests of their clients and uphold their moral duty to intervene on behalf of the animal $[80,95,96]$. Respondents also expressed concerns that lay contractors may offer services without the provision of pain relief, which not only normalises the practice, but may also intensify tensions regarding costs [97]. Previous studies have found that if it is perceived that their clients are concerned with costs, veterinarians are less likely to address options for pain management [66]. However, farmers may be receptive to changing current practices if they understand that pain management is associated with improved outcomes for animal health and welfare [98]. These outcomes include significant pain alleviation $[21,39,99,100]$, reduced pain-related behaviour $[2,33,101]$, and increased feed intake $[39,102-104]$. In addition to the costs associated with pain mitigation and its administration, veterinarians perceived that inadequate recognition of pain and ingrained 
practices are barriers to the provision of pain relief on-farm. While knowledge on pain recognition in cattle has developed considerably in recent years [105-107], there are concerns that developments in animal welfare science may not be accessible to farmers [108], therefore limiting the scope for scientific knowledge to challenge existing practices. Given that farmers perceive veterinarians as educators and advisors on matters of animal welfare $[96,109,110]$, veterinary-client communication plays an important role in the transfer of knowledge [96]. The ability for veterinarians to effectively translate knowledge on pain recognition, assessment, and management into on-farm application is therefore a pivotal issue worthy of greater support [98].

\subsection{Limitations}

The VCNZ relies on individual members to ensure that their details are current in their database. However, some of the electronic invitations to participate in the survey were undeliverable and returned. For this reason, the survey did not reach all members of the intended sample and a response rate cannot be accurately quantified. Despite this, the demographic data indicates a diverse range of respondents across gender, age, graduation year, and species emphasis. Furthermore, the age and gender distribution of the respondents in the current work is representative of the VCNZ Workforce Report [111].

\subsection{Implications}

Despite recognition that animals are capable of suffering from unmitigated pain, legislative protection of farm animals is limited [6,105,112-118]. In the current work, veterinarians associated multimodal pain relief with the greatest reduction of pain across all husbandry procedures in question. These perceptions align with current scientific knowledge $[21,27,29-34]$ and are views shared by veterinary authorities globally [119-121]. However, multimodal protocols are not a legal requirement in farm animals and remain significantly underused in practice $[21,29,35,36,42]$.

Although veterinarians in the present study rejected the use of differential treatment based on developmental age, the level of welfare protection afforded to young farm animals is inconsistent, representing a global welfare concern [34,105]. For instance, in New Zealand, rubber ring castration can be performed without any pain relief in calves up to 6 months of age [51], representing an example of policy that has not progressed with developments in animal welfare science. In contrast, rubber ring castration without an anaesthetic is limited to within the first week of life in the United Kingdom [122]. Legislation that requires the provision of pain relief after a specified developmental age underlies the assumption that calves in later stages of development are capable of suffering, and therefore require legal protection [123]. This is particularly problematic because it establishes an ontogeny of sentience that is not supported by scientific evidence.

Despite recent regulatory amendments introduced to address areas of highest risk to calf welfare in New Zealand, the resulting regulations have been criticised for favouring industry voices, incentivised to support standards that would otherwise fall below the general provisions of the Act $[117,118,124]$. The asymmetries that exist between current regulations and veterinary perspectives suggest that substantive changes are needed to improve New Zealand's animal welfare regime in line with current scientific knowledge. Given that veterinarians are considered an authority on matters of animal welfare [110,125], veterinary perceptions should be used to inform the development of standards of practice [37]. The current work reinforces the importance of the veterinary voice being heard on policy decisions for which it is eminently qualified to comment [126].

\section{Conclusions}

Despite developments in animal welfare science, which have led to a greater understanding of perioperative pain in calves, substantive legislative reforms are necessary in order to reconcile New Zealand's existing regulatory regime with veterinary perspectives. While certain demographic effects influenced perceptions towards perioperative pain man- 
agement, the current work revealed considerable support for strengthening the level of welfare protection afforded to calves in New Zealand, found in veterinarians' shared affinity for improving pain management protocols. Most veterinarians considered a multimodal approach as the most effective method for ameliorating perioperative pain, perceived that postprocedural pain persists beyond $24 \mathrm{~h}$ for castration and disbudding, and rejected differential treatment based on developmental age. Despite strong veterinary support for improving pain management protocols, veterinarians identified a number of barriers to pain mitigation on-farm, including costs, inadequate pain recognition, and ingrained farming practices. The knowledge gained from this research highlights the importance of the veterinary voice being heard on matters of animal welfare. Given the opportunity, veterinarians in New Zealand would likely support regulatory reform to strengthen the legal welfare protection afforded to calves in practice and policy.

Author Contributions: Conceptualization, R.v.D., A.M., and M.C.; methodology, R.v.D., A.M., and M.C.; formal analysis, R.v.D.; investigation, R.v.D.; data curation, R.v.D.; writing-original draft preparation, R.v.D.; writing-review and editing, R.v.D., A.M., and M.C.; supervision, A.M. and M.C.; project administration, R.v.D. All authors have read and agreed to the published version of the manuscript.

Funding: This research received no external funding.

Institutional Review Board Statement: The study was conducted according to the guidelines of the Royal (Dick) School of Veterinary Studies and approved by the University of Edinburgh Human (Research) Ethical Review Committee (HERC_269-18, 12-10-18).

Informed Consent Statement: Informed consent was obtained from all participants in the study.

Data Availability Statement: The data presented in this study, along with access to the survey, are available on request from the corresponding author. The data are not publicly available due to privacy reasons.

Acknowledgments: The authors wish to express gratitude to all veterinarians who participated in the survey, along with Timothy Willem Ruddell and Darren Shaw for assisting with aspects of the data analysis.

Conflicts of Interest: The authors declare no conflict of interest.

\section{References}

1. Meléndez, D.M.; Marti, S.; Pajor, E.A.; Sidhu, P.K.; Gellatly, D.; Moya, D.; Janzen, E.D.; Coetzee, J.F.; Schwartzkopf-Genswein, K.S. Effect of meloxicam and lidocaine administered alone or in combination on indicators of pain and distress during and after knife castration in weaned beef calves. PLoS ONE 2018, 13, e0207289. [CrossRef] [PubMed]

2. Thüer, S.; Mellema, S.; Doherr, M.G.; Wechsler, B.; Nuss, K.; Steiner, A. Effect of local anaesthesia on short- and long-term pain induced by two bloodless castration methods in calves. Vet. J. 2007, 173, 333-342. [CrossRef] [PubMed]

3. Weary, D.M.; Niel, L.; Flower, F.C.; Fraser, D. Identifying and preventing pain in animals. Appl. Anim. Behav. Sci. 2006, 100, 64-76. [CrossRef]

4. Anil, S.S.; Anil, L.; Deen, J. Challenges of pain assessment in domestic animals. J. Am. Vet. Med. Assoc. 2002, 220, 313-319. [CrossRef]

5. Farm Animal Welfare Council. Report on Priorities for Animal Welfare Research and Development; Ministry of Agriculture, Fisheries and Food: London, UK, 1993.

6. Thompson, C.S. Assessing Attitudes towards Welfare and Pain in Farm Animals. Ph.D. Thesis, The University of Edinburgh, Edinburgh, UK, November 2016.

7. Gleerup, K.B.; Andersen, P.H.; Munksgaard, L.; Forkman, B. Pain evaluation in dairy cattle. Appl. Anim. Behav. Sci. 2015, 171, 25-32. [CrossRef]

8. Guatteo, R.; Guémené, D. Sources of known and/or potential pain in farm animals. Adv. Anim. Biosci. 2014, 5, 319-332. [CrossRef]

9. Sutherland, M.A. Painful husbandry procedures and methods of alleviation: A review. Proc. N. Z. Soc. Anim. Prod. 2011, 71, 178-202.

10. Vasseur, E.; Borderas, F.; Cue, R.I.; Lefebvre, D.; Pellerin, D.; Rushen, J.; Wade, K.M.; de Passillé, A.M. A survey of dairy calf management practices in Canada that affect animal welfare. J. Dairy Sci. 2010, 93, 1307-1315. [CrossRef]

11. Boulton, A.; Kells, N.; Beausoleil, N.; Cogger, N.; Johnson, C.; Palmer, A.; Laven, R.; O’Connor, C.; Webster, J. Bobby Calf Welfare Across the Supply Chain-Final Report for Year 1; Technical Report: 2018/44; Ministry for Primary Industries: Wellington, New Zealand, 2018. 
12. Fisher, A.D.; Colditz, I.G.; Lee, C.F. The influence of land transport on animal welfare in extensive farming systems. J. Vet. Behav. 2009, 4, 157-162. [CrossRef]

13. Mellor, D.J.; Stafford, K.J. Animal welfare implications of neonatal mortality and morbidity in farm animals. Vet. J. 2004, 168, 118-133. [CrossRef]

14. Hulbert, L.E.; Moisá, S.J. Stress, immunity, and the management of calves. J. Dairy Sci. 2016, 99, 3199-3216. [CrossRef]

15. Sutherland, M.A.; Ballou, M.A.; Davis, B.L.; Brooks, T.A. Effect of castration and dehorning singularly or combined on the behavior and physiology of Holstein calves. J. Anim. Sci. 2013, 91, 935-942. [CrossRef]

16. Ballou, M.A.; Sutherland, M.A.; Brooks, T.A.; Hulbert, L.E.; Davis, B.L.; Cobb, C.J. Administration of anesthetic and analgesic prevent the suppression of many leukocyte responses following surgical castration and physical dehorning. Vet. Immunol. Immunopathol. 2013, 151, 285-293. [CrossRef]

17. Murray, C.F.; Fick, L.J.; Pajor, E.A.; Barkema, H.W.; Jelinski, M.D.; Windeyer, M.C. Calf management practices and associations with herd-level morbidity and mortality on beef cow-calf operations. Animal 2016, 10, 468-477. [CrossRef]

18. Adcock, S.J.J.; Tucker, C.B. The effect of disbudding age on healing and pain sensitivity in dairy calves. J. Dairy Sci. 2018, 101, 10361-10373. [CrossRef]

19. Low, L.A.; Fitzgerald, M. Acute pain and a motivational pathway in adult rats: Influence of early life pain experience. PLoS ONE 2012, 7, e34316. [CrossRef]

20. McCracken, L.; Waran, N.; Mitchinson, S.; Johnson, C.B. Effect of age at castration on behavioural response to subsequent tail docking in lambs. Vet. Anaesth. Analg. 2010, 37, 375-381. [CrossRef]

21. Hudson, C.; Whay, H.; Huckley, J. Recognition and management of pain in cattle. Practice 2008, 30, 126-134. [CrossRef]

22. Marti, S.; Meléndez, D.M.; Pajor, E.A.; Moya, D.; Heuston, C.E.M.; Gellatly, D.; Janzen, E.D.; Schwartzkopf-Genswein, K.S. Effect of band and knife castration of beef calves on welfare indicators of pain at three relevant industry ages: II. Chronic pain. J. Anim. Sci. 2017, 10, 4367-4380. [CrossRef]

23. Mirra, A.; Spadavecchia, C.; Bruckmaier, R.; Gutzwiller, A.; Casoni, D. Acute pain and peripheral sensitization following cautery disbudding in 1- and 4-week-old calves. Physiol. Behav. 2018, 184, 248-260. [CrossRef]

24. Mellor, D.; Stafford, K. Assessing and minimising the distress caused by painful husbandry procedures in ruminants. Practice 1999, 21, 436-446. [CrossRef]

25. Mellor, D.J.; Murray, L. Changes in the cortisol responses of lambs to tail docking, castration and ACTH injection during first seven days after birth. Res. Vet. Sci. 1989, 46, 392-395. [CrossRef]

26. Doherty, T.J.; Kattesh, H.G.; Adcock, R.J.; Welborn, M.G.; Saxton, A.M.; Morrow, J.L.; Dailey, J.W. Effects of a concentrated lidocaine solution on the acute phase stress response to dehorning in dairy calves. J. Dairy Sci. 2007, 90, 4232-4239. [CrossRef] [PubMed]

27. Herskin, M.S.; Nielsen, B.H. Welfare Effects of the Use of a Combination of Local Anesthesia and NSAID for Disbudding Analgesia in Dairy Calves-Reviewed Across Different Welfare Concerns. Front. Vet. Sci. 2018, 5, 117. [CrossRef] [PubMed]

28. Stewart, M.; Stookey, J.M.; Stafford, K.J.; Tucker, C.B.; Rogers, A.R.; Dowling, S.K.; Verkerk, G.A.; Schaefer, A.L.; Webster, J.R. Effects of local aanesthetic and a nonsteroidal anti-inflammatory drug on pain responses of dairy calves to hot-iron dehorning. J. Dairy Sci. 2009, 92, 1512-1519. [CrossRef] [PubMed]

29. Viñuela-Fernández, I.; Jones, E.; Welsh, E.M.; Fleetwood-Walker, S.M. Pain mechanisms and their implication for the management of pain in farm and companion animals. Vet. J. 2007, 174, 227-239. [CrossRef]

30. Coetzee, J.F. A review of pain assessment techniques and pharmacological approaches to pain relief after bovine castration: Practical implications for cattle production within the United States. Appl. Anim. Behav. Sci. 2011, 135, 192-213. [CrossRef]

31. Coetzee, J.F. Assessment and Management of Pain Associated with Castration in Cattle. Vet. Clin. Food Anim. 2013, 29 , 75-101. [CrossRef]

32. Weary, D.M.; von Keyserlingk, M.A.G. The welfare of dairy calves. Am. Assoc. Bov. Pract. Proc. 2008, 41, 8-11.

33. Winder, C.B.; Miltenburg, C.L.; Sargeant, J.M.; LeBlanc, S.J.; Haley, D.B.; Lissemore, K.D.; Godkin, M.A.; Duffield, T.F. Effects of local anesthetic or systemic analgesia on pain associated with cautery disbudding in calves: A systematic review and meta-analysis. J. Dairy Sci. 2018, 101, 5411-5427. [CrossRef]

34. Costa, J.H.C.; Cantor, M.C.; Adderley, N.A.; Neave, H.W. Key animal welfare issues in commercially raised dairy calves: Social environment, nutrition, and painful procedures. Can. J. Anim. Sci. 2019, 99, 649-660. [CrossRef]

35. Hewson, C.J.; Dohoo, I.R.; Lemke, K.A.; Barkema, H.W. Canadian veterinarians' use of analgesics in cattle, pigs, and horses in 2004 and 2005. Can. Vet. J. 2007, 48, 155-164.

36. Tschoner, T.; Sauter-Louis, C.; Peinhofer, V.; Feist, M. Attitudes of Bavarian bovine veterinarians towards pain and pain management in cattle. Vet. Rec. 2020, 187, e90. [CrossRef]

37. Fajt, V.R.; Wagner, S.A.; Norby, B. Analgesic drug administration and attitudes about analgesia in cattle among bovine practitioners in the United States. J. Am. Vet. Med. 2011, 238, 755-767. [CrossRef]

38. Huxley, J.N.; Whay, H.R. Current attitudes of cattle practitioners to pain and the use of analgesics in cattle. Vet. Rec. 2006, 159, 662-668. [CrossRef]

39. Faulkner, P.M.; Weary, D.M. Reducing pain after dehorning in dairy calves. J. Dairy Sci. 2000, 83, 2037-2041. [CrossRef]

40. Heinrich, A.; Duffield, T.F.; Lissemore, K.D.; Millman, S.T. The effect of meloxicam on behaviour and pain sensitivity of dairy calves following cautery dehorning with a local anesthetic. J. Dairy Sci. 2010, 93, 2450-2457. [CrossRef] 
41. Stilwell, G.; Lima, M.S.; Carvalho, R.C.; Broom, D.M. Effects of hot-iron disbudding, using regional anaesthesia with and without carprofen, on cortisol and behaviour of calves. Res. Vet. Sci. 2012, 92, 338-341. [CrossRef]

42. Hambleton, S.Y.N.; Gibson, T.G. Study investigating the attitudes and opinions of cattle farmers and veterinarians in the UK on the use of non-steroidal and anti-inflammatory drugs (NSAIDs) for post-disbudding analgesia of calves. Anim. Welf. 2017, 26, 323-334. [CrossRef]

43. Laven, R.A.; Huxley, J.N.; Whay, H.R.; Stafford, K.J. Results of a survey of attitudes of dairy veterinarians in New Zealand regarding painful procedures and conditions in cattle. N. Z. Vet. J. 2009, 57, 215-220. [CrossRef]

44. Thomsen, P.T.; Anneberg, I.; Herskin, M.S. Differences in attitudes of farmers and veterinarians towards pain in dairy cows. Vet. J. 2012, 194, 94-97. [CrossRef] [PubMed]

45. Allen, K.A.; Coetzee, J.F.; Edwards-Callaway, L.N.; Glynn, H.; Dockweiler, J.; KuKanich, B.; Lin, H.; Wang, C.; Fraccaro, E.; Jones, M.; et al. The effect of timing of oral meloxicam administration on physiological responses in calves after cautery dehorning with local anesthesia. J. Dairy Sci. 2013, 96, 5194-5205. [CrossRef] [PubMed]

46. Becker, J.; Doherr, M.G.; Bruckmaier, R.M.; Bodmer, M.; Zanolari, P.; Steiner, A. Acute and chronic pain in calves after different methods of rubber-ring castration. Vet. J. 2012, 194, 380-385. [CrossRef] [PubMed]

47. Hötzel, M.J.; Longo, C.; Balcão, L.F.; Cardoso, C.S.; Costa, J.H. A survey of management practices that influence performance and welfare of dairy calves reared in southern Brazil. PLOS ONE 2014, 15, e114995. [CrossRef]

48. Ministry for Primary Industries. Proposed Animal Welfare Regulations (Care E Conduct and Surgical E Painful Procedures); Ministry for Primary Industries: Wellington, New Zealand, 2016.

49. Ministry for Primary Industries. Animal Welfare Regulation Development Workshops and Meetings; Ministry for Primary Industries: Wellington, New Zealand, 2015.

50. Wivagg, J. Forced Choice. In Encyclopedia of Survey Research Methods; Lavrakas, P.J., Ed.; Sage Publications: London, UK, 2008; pp. 289-290.

51. Ministry for Primary Industries. Significant Surgical Procedures Regulatory Policies; Ministry for Primary Industries: Wellington, New Zealand, 2019.

52. Hötzel, M.J.; Sneddon, J.N. The role of extensionists in Santa Catarina, Brazil, in the adoption and rejection of providing pain relief to calves for dehorning. J. Dairy Sci. 2013, 96, 1535-1548. [CrossRef]

53. Whay, H.R.; Huxley, J. Pain relief in cattle: A practitioners perspective. Cattle Pract. 2005, 13, 81-85.

54. Remnant, J.G.; Tremlett, A.; Huxley, J.N.; Hudson, C.D. Clinician attitudes to pain and use of analgesia in cattle: Where are we 10 years on? Vet. Rec. 2017, 181, 400. [CrossRef]

55. Barkema, H.W.; von Keyserlingk, M.A.G.; Katelic, J.P.; Lam, T.J.; Luby, C.; Roy, J.P.; LeBlanc, S.J.; Keefe, G.P.; Kelton, D.F. Invited review: Changes in the dairy industry affecting dairy cattle health and welfare. J. Dairy Sci. 2015, 98, 7426-7445. [CrossRef]

56. Wikman, I.; Hokkanen, A.H.; Pastell, M.; Kauppinen, A.; Valros, A.; Hänninen, L. Dairy producer attitudes to pain in cattle in relation to disbudding calves. J. Dairy Sci. 2013, 96, 6894-6903. [CrossRef]

57. Kristensen, E.; Enevoldsen, C. A mixed methods inquiry: How dairy farmers perceive the value(s) of their involvement in an intensive dairy herd health management program. Acta Vet. Scand. 2008, 50, 50. [CrossRef]

58. Chambers, J.P.; Stafford, K.J.; Mellor, D.J. Analgesics: What use are they in farm animals? Proc. N. Z. Soc. Anim. Prod. 2002, 62, 359-362.

59. Stafford, K.J.; Chambers, J.P.; Mellor, D.J. The alleviation of pain in cattle: A review. CAB Rev. 2006, 1, 7. [CrossRef]

60. Robbins, J.A.; Weary, D.M.; Schuppli, C.A.; von Keyserlingk, M.A.G. Stakeholder views on treating pain due to dehorning dairy calves. Anim. Welf. 2015, 24, 399-406. [CrossRef]

61. Lorena, S.E.; Luna, S.P.; Lascelles, D.X.; Corrente, J.E. Attitude of Brazilian veterinarians in the recognition and treatment of pain in horses and cattle. Vet. Anaesth. Analg. 2013, 40, 410-418. [CrossRef]

62. Raekallio, M.; Heinonen, K.M.; Kuussaari, J.; Vainio, O. Pain Alleviation in Animals: Attitudes and Practices of Finnish Veterinarians. Vet. J. 2003, 165, 131-135. [CrossRef]

63. Ellingsen, K.; Mejdell, C.M.; Hansen, B. Veterinarians' and agricultural advisors' perception of calf health and welfare in organic dairy production in Norway. Org. Agric. 2012, 2, 67-77. [CrossRef]

64. Misch, L.J.; Duffield, T.F.; Millman, S.T.; Lissemore, K.D. An investigation into the practices of dairy producers and veterinarians in dehorning dairy calves in Ontario. Can. Vet. J. 2007, 48, 1249-1254.

65. Ventura, B.A.; Weary, D.M.; Giovanetti, A.S.; von Keyserlingk, M.A.G. Veterinary perspectives on cattle welfare challenges and solutions. Livestig. Sci. 2016, 193, 95-102. [CrossRef]

66. Winder, C.B.; LeBlanc, S.J.; Haley, D.B.; Lissemore, K.D.; Godkin, M.A.; Duffield, T.F. Practices for the disbudding and dehorning of dairy calves by veterinarians and dairy producers in Ontario, Canada. J. Dairy Sci. 2016, 99, 10161-10173. [CrossRef]

67. van Dyke, R.; Miele, A.; Connor, M. An Investigation into the Perceptions of Veterinarians towards Calf Welfare in New Zealand. Animals 2021, 11, 421. [CrossRef]

68. Dillman, D. Mail and Internet Surveys: The Tailored Design Method; Wiley: Hoboken, NJ, USA, 2007.

69. Bowling, A. Mode of questionnaire administration can have serious effects on data quality. J. Public Health 2005, $27,281-291$. [CrossRef] [PubMed]

70. Dillman, D.A. Mail and Internet Surveys: The Tailored Design Method, 2nd ed.; John Wiley and Sons: New York, NY, USA, 2000. 
71. Huber, J.; Arnholdt, T.; Mostl, E.; Gelfert, C.-C.; Drillich, M. Pain management with flunixin meglumine at dehorning of calves. J. Dairy Sci. 2013, 96, 132-140. [CrossRef] [PubMed]

72. Laurence, M.; Barnes, A.; Collins, T.; Hyndman, T.; Musk, G.C. Assessing and mitigating post-operative castration pain in Bos indicus cattle. Anim. Prod. Sci. 2016, 58, 909-919. [CrossRef]

73. New Zealand Veterinary Association. Pain and Its Alleviation. Available online: https://nzva.site-ym.com/page/policypainallev (accessed on 22 March 2021).

74. Capner, C.A.; Lascelles, B.D.X.; Waterman-Pearson, A.E. Current British veterinary attitudes to perioperative analgesia for dogs. Vet. Rec. 1999, 145, 95-99. [CrossRef]

75. Kielland, C.; Skjerve, E.; Zanella, A.J. Attitudes of veterinary students to pain in cattle. Vet. Rec. 2009, 165, 254-258. [CrossRef]

76. Paul, E.S.; Podberscek, A.L. Veterinary education and students' attitudes towards animal welfare. Vet. Rec. 2000, 146, 269-272. [CrossRef]

77. Colombo, E.S.; Crippa, F.; Calderari, T.; Prato-Previde, E. Empathy toward animals and people: The role of gender and length of service in a sample of Italian veterinarians. J. Vet. Behav. 2017, 17, 32-37. [CrossRef]

78. Heleski, C.R.; Mertig, A.G.; Zanella, A.J. Assessing attitudes toward farm animal welfare: A national survey of animal science faculty members. J. Anim. Sci. 2004, 82, 2806-2814. [CrossRef]

79. Dohoo, S.E.; Dohoo, I.R. Factors influencing the postoperative use of analgesics in dogs and cats by Canadian veterinarians. Can. Vet. J. 1996, 37, 552-555.

80. Meijboom, F.L. More than just a vet? Professional integrity as an answer to the ethical challenges facing veterinarians in animal food production. Food Ethics 2018, 1, 209-220. [CrossRef]

81. Ostovic, M.; Mikus, T.; Pavicic, Z.; Matkovic, K.; Mesic, Z. Influence of socio-demographic and experiential factors on the attitudes of Croatian veterinary students towards farm animal welfare. Vet. Med. 2017, 62, 417-428. [CrossRef]

82. Proudfoot, K.L.; Ventura, B.A. Impact of a Frame Reflection Assignment on Veterinary Student Perspectives toward Animal Welfare and Differing Viewpoints. J. Vet. Med. Educ. 2020, 48, 361-372. [CrossRef] [PubMed]

83. González, L.A.; Schwartzkopf-Genswein, K.S.; Caulkett, N.A.; Janzen, E.; McAllister, T.A.; Fierheller, E.; Schaefer, A.L.; Haley, D.B.; Stookey, J.M.; Hendrick, S. Pain mitigation after band castration of beef calves and its effects on performance, behavior, Escherichia coli, and salivary cortisol. J. Anim. Sci. 2013, 88, 802-810. [CrossRef] [PubMed]

84. Petherick, J.C.; Small, A.H.; Mayer, D.G.; Colditz, I.G.; Ferguson, D.M.; Stafford, K.J. A comparison of welfare outcomes for weaner and mature Bos indicus bulls surgically or tension band castrated with or without analgesia: 1 . Behavioural responses. App. Anim. Behav. Sci. 2014, 157, 23-34. [CrossRef]

85. Stafford, K.J.; Mellor, D.J.; Todd, S.E.; Bruce, R.A.; Ward, R.N. Effect of local anaesthesia or local anaesthesia plus a non-steroidal anti inflammatory drug on the acute cortisol response of calves to five different methods of castration. Res. Vet. Sci. 2002, 73, 61-70. [CrossRef]

86. Main, D.C.J. Evolution of Animal-Welfare Education for Veterinary Students. J. Vet. Med. Educ. 2010, 37, 30-35. [CrossRef]

87. Marchant-Forde, J.N. The science of animal behavior and welfare: Challenges, opportunities, and global perspective. Front. Vet. Sci. 2015, 2, 16. [CrossRef]

88. Stilwell, G.; Windsor, P.; Broom, D.M. Pain Management for Ruminants During Common Farm Husbandry Procedures. In Advances in Animal Health, Medicine and Production; Duarte, A.F., da Costa, L.L., Eds.; University of Lisbon: Lisbon, Portugal, 2020; pp. 27-51.

89. Tschoner, T. Methods for Pain Assessment in Calves and Their Use for the Evaluation of Pain during Different Procedures-A Review. Animals 2021, 11, 1235. [CrossRef]

90. Canozzi, M.E.A.; Borges, J.A.R.; Barcellos, J.O.J. Attitudes of cattle veterinarians and animal scientists to pain and painful procedures in Brazil. Prev. Vet. Med. 2020, 177, 104909.

91. Fulwider, W.K.; Grandin, T.; Rollin, B.E.; Engle, T.E.; Dalsted, N.L.; Lamm, W.D. Survey of Dairy Management Practices on One Hundred Thirteen North Central and Northeastern United States Dairies. J. Dairy Sci. 2008, 91, 1686-1692. [CrossRef]

92. Gottardo, F.; Nalon, E.; Contiero, B.; Normando, S.; Dalvit, P.; Cozzi, G. The dehorning of dairy calves: Practices and opinions of 639 farmers. J. Dairy Sci. 2011, 94, 5724-5734. [CrossRef] [PubMed]

93. Sumner, C.L.; von Keyserlingk, M.A.G. Canadian dairy cattle veterinarian perspectives on calf welfare. J. Dairy Sci. 2018, 101, 10303-10316. [CrossRef] [PubMed]

94. Huxley, J.; Whay, H.R. Attitudes of UK veterinary surgeons and cattle farmers to pain and the use of analgesics in cattle. Cattle Pract. 2007, 15, 189-193.

95. Hernandez, E.; Fawcett, A.; Brouwer, E.; Rau, J.; Turner, P.V. Speaking Up: Veterinary Ethical Responsibilities and Animal Welfare Issues in Everyday Practice. Animals 2018, 8, 15. [CrossRef]

96. Sumner, C.L. Promoting Farmer and Veterinarian Cooperation to Improve Dairy Calf Welfare. Ph.D. Thesis, The University of British Columbia, Vancouver, BC, Canada, September 2018.

97. Kaske, M.; Scheidegger, R.; Bähler, C.; Markov, J.; Sidler, X. Interventions and treatments of farm animals by non-veterinarians: Quo vadis? Schweiz. Arch. Tierheilkd. 2020, 162, 83-92. [CrossRef]

98. Kristensen, E.; Jakobsen, E.B. Challenging the myth of the irrational dairy farmer; understanding decision-making related to herd health. N. Z. Vet. J. 2011, 59, 1-7. [CrossRef] 
99. Stilwell, G.; Lima, M.S.; Broom, D.M. Effects of nonsteroidal anti-inflammatory drugs on long-term pain in calves castrated by use of an external clamping technique following epidural anesthesia. Am. J. Vet. Res. 2008, 69, 744-750. [CrossRef]

100. Stilwell, G.; Lima, M.S.; Broom, D.M. Comparing plasma cortisol and behaviour of calves dehorned with caustic paste after non-steroidal-anti-inflammatory analgesia. Livestock Sci. 2008, 119, 63-69. [CrossRef]

101. Stafford, K.J.; Mellor, D.J. Addressing the pain associated with disbudding and dehorning in cattle. App. Anim. Behav. Sci. 2011, 135, 226-231. [CrossRef]

102. Bates, A.J.; Laven, R.A.; Chapple, F.; Weeks, D.S. The effect of different combinations of local anaesthesia, sedative and nonsteroidal anti-inflammatory drugs on daily growth rates of dairy calves after disbudding. N. Z. Vet. J. 2016, 64, $282-287$. [CrossRef]

103. Heinrich, A.; Duffield, T.F.; Lissemore, K.D.; Squires, E.J.; Millman, S.T. The impact of meloxicam on post-surgical stress associated with cautery dehorning. J. Dairy Sci. 2009, 92, 540-547. [CrossRef]

104. Espinoza, C. Topical anaesthesia provides pain management for dehorning of calves. J. Dairy Sci. 2013, 96, 2894-2902. [CrossRef]

105. McLennan, K.M. Why Pain Is Still a Welfare Issue for Farm Animals, and How Facial Expression Could Be the Answer. Agriculture 2018, 8, 127. [CrossRef]

106. Müller, B.R.; Soriano, V.S.; Bellio, J.C.B.; Molento, C.F.M. Facial expression of pain in Nellore and crossbred beef cattle. J. Vet. Behav. 2019, 34, 60-65. [CrossRef]

107. Windsor, P.A.; Lomax, S.; White, S.L.P. Progress in pain management to improve small ruminant farm welfare. Small Ruminant Res. 2016, 142, 55-57. [CrossRef]

108. Bran, J.A.; Daros, R.R.; von Keyserlingk, M.A.G.; Hötzel, M.J. Lameness on Brazilian pasture based dairies—Part 1: Farmers' awareness and actions. Prev. Vet. Med. 2018, 157, 134-141. [CrossRef]

109. Robles, I.; Arruda, A.G.; Nixon, E.; Johnstone, E.; Wagner, B.; Edwards-Callaway, L.; Baynes, R.; Coetzee, J.; Pairis-Garcia, M. Producer and Veterinarian Perspectives towards Pain Management Practices in the US Cattle Industry. Animals 2021, 11, 209. [CrossRef]

110. Pothmann, H.; Nechanitzky, K.; Sturmlechner, F.; Drillich, M. Consultancy to dairy farmers relating to animal health and herd health management on small- and medium-sized farms. J. Dairy Sci. 2014, 97, 851-860. [CrossRef]

111. Veterinary Council of New Zealand. The New Zealand Veterinary Workforce in 2017-2018; Veterinary Council of New Zealand: Wellington, New Zealand, 2018.

112. Fraser, D.; Koralesky, K.E.; Urton, G. Toward a harmonized approach to animal welfare law in Canada. Can. Vet. J. 2018, 59, 293-302.

113. Fiber-Ostrow, P.; Jarret, S.L. Behind a veil of secrecy: Animal abuse, factory farms, and Ag-Gag legislation. Contemp. Justice Rev. 2016, 2, 230-249. [CrossRef]

114. Morton, R.; Hebart, M.L.; Whittaker, A.L. Explaining the Gap Between the Ambitious Goals and Practical Reality of Animal Welfare Law Enforcement: A Review of the Enforcement Gap in Australia. Animals 2020, 10, 482. [CrossRef]

115. Bruce, A.; Faunce, T. Food Production and Animal Welfare Legislation in Australia: Failing Both Animals and the Environment. In International Farm Animal, Wildlife and Food Safety Law; Steier, G., Patel, K.K., Eds.; Springer: Cham, Switzerland, 2017 ; pp. 359-394.

116. Ferrere, M.R. Animal Welfare in New Zealand: Oversight, Compliance and Enforcement; The University of Otago: Otago, New Zealand, 2019.

117. Ferrere, M.R. Codes vs. regulations: How best to enforce animal welfare in New Zealand? Altern. Law J. 2018, 43, 250-256. [CrossRef]

118. Morris, M.C. The Use of Animals in New Zealand: Regulation and Practice. Soc. Anim. 2011, 19, 368-382. [CrossRef]

119. British Veterinary Association. Available online: https://www.bcva.org.uk/system/files/whatwedo/Analgesia\%20in\%20calves. pdf (accessed on 28 May 2021).

120. New Zealand Veterinary Association. Available online: https://nzva.site-ym.com/page/policydehorning (accessed on 28 May 2021).

121. American Veterinary Medical Association. Available online: https://www.avma.org/resources-tools/avma-policies/castrationand-dehorning-cattle (accessed on 28 May 2021).

122. Department for Environment, Food and Rural Affairs. Available online: https://www.gov.uk/government/publications/codeof-recommendations-for-the-welfare-of-livestock-cattle (accessed on 22 May 2021).

123. Campbell, M.L.H.; Mellor, D.J.; Sandøe, P. How should the welfare of fetal and neurologically immature postnatal animals be protected? Anim. Welf. 2014, 23, 369-379. [CrossRef]

124. Knight, A. Should New Zealand Do More to Uphold Animal Welfare? Anim. Stud. J. 2020, 9, 114-149. [CrossRef]

125. Derks, M.; van Werven, T.; Hogeveen, H.; Kremer, W.D.J. Veterinary herd health management programs on dairy farms in the Netherlands: Use, execution, and relations to farmer characteristics. J. Dairy Sci. 2013, 96, 1623-1637. [CrossRef]

126. Blayney, N. Veterinary Voice. Vet. Rec. 2008, 162, 387. [CrossRef] 